\title{
Can Public Transportation Compete with Automated and Connected Cars?
}

\author{
Ralph Buehler \\ Virginia Tech Alexandria Center
}

\begin{abstract}
Over the next 30 years, technological innovation will make automobile travel more convenient. Automated and connected vehicles will perform an increasing number of driving tasks without human input and will lure customers away from traditional public transportation. This paper first explores key characteristics of public transportation demand in the United States today-based on an international comparison with other Western countries. Next, the paper provides potential pathways on how public transportation agencies and local governments in the United States could respond to the emergence of automated and connected vehicles. The paper argues that space efficiency in urbanized areas and the rush hour commute will remain public transportation's key strengths. In addition, public transportation will retain its important role in providing mobility for all-in particular, for those who cannot afford costly automated and connected vehicles. To remain competitive with the car, public transportation agencies and governments have to harness emerging automated and connected technologies for public transportation, integrate public transportation with other mobility services, coordinate and integrate public transportation services regionally, and coordinate planning for public transportation and land use.
\end{abstract}

Key Words: public transportation, automated and connected vehicles, future, United States

\section{Introduction}

Over the next 30 years, technological innovation will make automobile travel more convenient. Automobiles will perform more and more driving and safety tasks without driver input, relying on sensors and connected technology to communicate with other vehicles and infrastructure (USDOT 2017). Eventually, the car industry's goal is to achieve fully automated and connected vehicles that allow individuals to engage in activities other than driving a carmimicking one of public transportation's competitive advantages. Even during the transition towards fully automated and connected vehicles, more convenient car travel has the potential to lure passengers away from traditional public transportation.

(C) 2018 Ralph Buehler

http//dx.doi.org/10.5038/2375-0901.21.1.2

ISSN: 1077-291X | Licenced under Creative Commons License Attribution - Noncommercial 4.0

The Journal of Public Transportation is published by the Center for Urban Transportation Research at the University of South Florida 
The speed of technology development and transition toward automated and connected vehicles is unknown (Zmud et al. 2015). Moreover, it is also difficult to predict possible shifts in societal preferences for technology, automation, sharing, and urban living. Other unidentified trends in societal preferences, socio-economics, demographics, and land use complicate specific predictions about public transportation's future in 30 years.

Whatever the trends, actions of public transportation agencies and governments will shape transit's future attractiveness and competitiveness. This includes exploring the use of emerging automated and connected technologies for public transportation, integrating public transportation with other mobility services, regional coordination and integration of public transportation services, coordinating planning for public transportation and land use, as well as providing customer-oriented, convenient, and reliable public transportation service.

This paper first highlights characteristics of current public transportation demand in the United States-based on an international comparison with other high-income Western countries. These factors are the basis for any future trends in public transportation over the next 30 years. The paper then focuses on public transportation's future challenge of competing with more attractive and convenient car travel-achieved by increasingly automated and connected vehicles. The rest of the paper provides potential pathways for public transportation agencies to respond to this challenge.

\section{Characteristics of Public Transportation in the United States}

Compared to other wealthy Western countries in North America and Europe, demand for public transportation in the United States is low-both measured as share of trips and ridership per capita. Figure 1 shows variability in the share of daily trips made by public transportation in Europe and the United States-limited to countries with recent national travel survey data for all trip purposes. At the high end, the Swiss made almost one-quarter of their daily trips (24\%) by public transportation. This share is 12 times greater than public transportation's share of trips in the United States (2\%) - the country at the low end of the spectrum. Austria (17\%) and Sweden (14\%) are leading the large midfield of this distribution including Germany (12\%), Great Britain (10\%), Norway (10\%), France (8\%), and Finland (8\%). Compared to other European countries, Denmark (6\%) and the Netherlands (6\%) have low trip shares of public transportation. One reason may be the high shares of trips taken by bicycle in the two countries: 29\% for the Netherlands and 15\% in Denmark (Buehler \& Pucher 2012). 


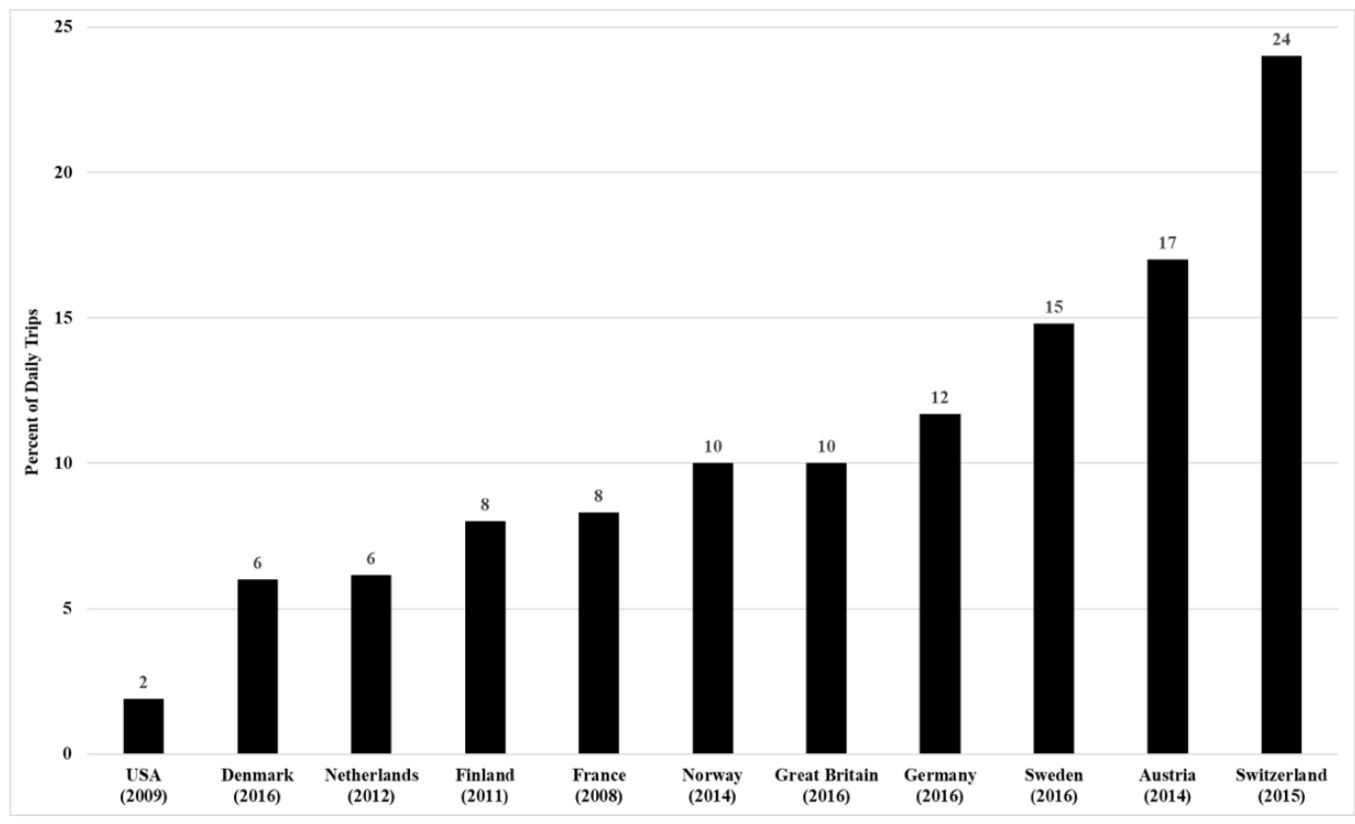

\section{FIGURE 1.}

Percentage Share of Daily Trips Made by Public Transport (latest available year), 2008-2016

Note: Travel survey results are not fully comparable between countries due to differences in survey methodologies and definitions: (BFS 2017; BMVIT 2016; DfT 2017; DMT 2017; MOP 2017; OMNIL 2011; SIKA 2017; TOI 2015; USDOT 2010; WSP 2011).

Figure 2 displays the most recent statistics on annual public transportation trips per capita for the United States, Canada, and select European countries with available data. As in Figure 1, Switzerland has the highest demand for public transportation: 246 trips per inhabitant per year. Swiss demand for public transportation is roughly 11 times greater than the annual number of public transportation trips per person in the United States-the country with the lowest per-capita ridership in Figure 2. Canada, the other North American country included in Figure 2, has almost three times more public transportation trips per capita (58) than the United States. 


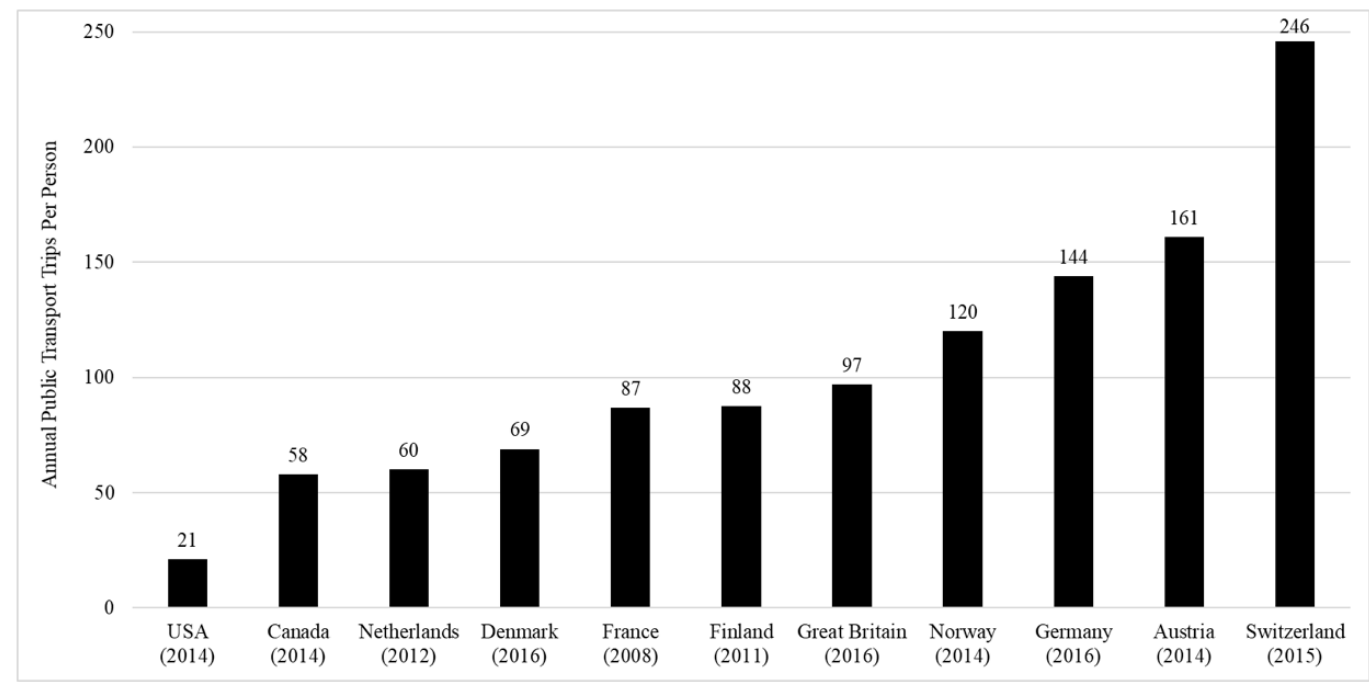

FIGURE 2.

Number of Annual Public Transport Trips per Person (latest available year), 2008-2016

Note: Travel survey results are not fully comparable between countries due to differences in survey methodologies and definitions. Passenger trips are reported as "linked trips" (APTA 2017; BFS 2017; BMVIT 2016; DfT 2017; DMT 2017; MOP 2017; OMNIL 2011; TOI 2015; WSP 2011).

Several factors account for lower public transport ridership in the United States than in Europe and Canada. First, the USA has overall lower population densities and more lowdensity suburban sprawl often with strict government mandated separation of land uses. Low population densities are difficult to serve efficiently by public transportation (TRB 2001; Vuchic 2005). Second, compared to other Western countries, Americans enjoy a low cost of driving -in terms of lower taxes on gasoline, vehicle registration, and the purchase of new cars. This contributes to high levels of car ownership in the United States. Easy availability of cars and a low cost of driving makes it difficult for public transportation to compete (Buehler \& Pucher, 2012; Newmann \& Kenworthy, 2011). Third, most communities and states in the USA provide ample roadway capacity and free car parking for the majority of trips. Traffic engineering standards_called level of service-focus on moving cars as smoothly as possible. Local or state legislation typically mandates a minimum supply of parking spaces for homes, workplaces, and businesses. Convenient car travel with free car parking makes driving very attractive (Shoup 2011). Lastly, several studies have found less and lower quality public transportation supply in the United States compared to other countries (Buehler \& Pucher 2012; TRB 2001). Thus, Americans choose to make the vast majority of their trips by other modes than by public transportation.

Like in most Western countries, in the United States public transportation's share of trips for the work commute is greater than for all trips. As seen in Figure 1 above, public transportation accounts for only $2 \%$ of all trips in the United States. However, $5.3 \%$ of commuters -7.8 million people-reported regularly riding public transportation to and from work in 2015 (APTA 2017). Especially for the commute to workplaces downtown, public transportation has a competitive advantage compared to driving. Public transportation is more space efficient and can easily move large volumes of riders during peak hours (Pucher 2004; Vuchic 2005). Comparative studies 
suggest that public transportation in the United States is more commute oriented than in other countries. For example, $35 \%$ of public transport trips in the United States were commute or work related compared to only $24 \%$ in Germany (Buehler \& Pucher 2012).

As in other countries, public transportation ridership in the United States is highest in urbanized areas. In fact, almost $70 \%$ of public transportation trips in the United States are concentrated in just six large metropolitan areas (APTA 2017). In 2014, public transportation agencies headquartered in the New York City area alone accounted for roughly 4 in 10 (41\%) of all unlinked passenger trips in the USA. Jointly, public transportation agencies headquartered in the San Francisco, Boston, Washington, DC, Philadelphia, and Chicago metropolitan areas accounted for another $28 \%$ of all public transportation trips taken in the United States in 2014 (APTA 2017).

As in other countries, public transportation ridership is typically highest in the center city. For example, in $2011,14 \%$ of all trips in the New York City metropolitan area were by public transportation compared to $27 \%$ of all trips and $57 \%$ of commutes by public transportation within New York City (NYMTC 2014). Similarly, 10\% of trips in the Washington, DC, region were by public transportation, while $22 \%$ of all trips and $37 \%$ of commutes in Washington, DC, were by public transportation (Buehler Jung, \& Hamre 2015; MWCOG 2010).

Other key differences between public transportation demand in the United States and European countries include a higher share of public transportation trips by bus and a large income gap between bus and rail passengers. According to national household travel surveys for $2008 / 2009$, buses accounted for $72 \%$ of public transportation trips in the United States compared to only $42 \%$ in Germany (Buehler \& Pucher 2012). Official data reported by the American Public Transportation Association (APTA 2017) identify a lower bus share (50\%) of public transportation trips-but still higher than in Germany. Rail passengers in the United States have much higher incomes than bus riders. According to the NHTS 2008/2009, annual median household incomes for rail passengers were three times greater than for bus riders: $\$ 72,000$ vs. $\$ 22,000$. By contrast, Germany's national travel survey reports no difference in median income between bus and rail riders (Buehler \& Pucher 2012).

\section{More Convenient Car Travel and Public Transportation's Response}

This section first highlights the emergence of connected and automated vehicles (CAVs) for passenger transportation as a key challenge influencing public transportation demand over the next 30 years. CAVs can perform (some) driving or safety functions without driver input by using vehicle sensors and connected technology to communicate with other vehicles and infrastructure (USDOT 2017). Next, the paper highlights potential responses for public transportation agencies to increase public transportation's competitiveness. This includes exploring the use of emerging automated and connected technologies for public transportation, integrating public transportation with other mobility services, regional coordination and integration of public transportation services, and coordinating planning for public transportation and land use. 


\section{The Challenge of Increasingly Automated and Connected Vehicles}

The exact timing for the transition toward CAVs is still unclear. The speed of the transition depends on private sector innovation, public acceptance, government regulations, and public sector investments in infrastructure for connected vehicles (Zmud et al. 2015). Achieving a fully connected and automated vehicle (CAV) fleet will likely take much longer than the 30-year planning horizon discussed in this paper (Litman 2017). A time when only CAVs, unsupervised by human drivers, will dominate city streets under any weather condition is still far off in the future.

However, over the next 30 years vehicles will become increasingly automated, as well as connected to each other and to public infrastructure. Some driver assist and partial driving automation features are already standard in many new (luxury) cars today, including parking assistance, lane detection, braking assistance, blind spot monitoring, adaptive cruise control, and others (Litman 2017). Effects of entirely self-driving CAVs on car ownership and car travel demand are still unclear. If most CAVs are privately owned, car ownership levels could increase. If CAVs will be part of carsharing-like programs with robotic cars ordered on-demand, car ownership rates may fall. If CAVs are not privately owned, they could reduce vehicle miles traveled (VMT) through ridesharing. However, even in that scenario VMT may increase due to greater convenience of car travel, greater suburban sprawl related to the reduced time-cost of driving, and more people driving in robotic cars (e.g., those who cannot drive legally today).

No matter how the transition will play out, changes toward increasingly automated and connected vehicles hold potential threats for the future demand for public transportation in the United States. CAVs will increase the convenience of driving and thus lure people away from traditional public transportation-especially where public transportation service is sparse, unreliable, and of low quality. In some ways, in developing fully automated and connected vehicles the car industry strives to mimic one of public transportation's competitive advantages by allowing individuals to engage in activities other than driving a car. Lower time-costs of car travel may further increase suburban sprawl-creating more areas that are difficult to serve by public transportation. Additionally, technological innovation in the automobile sector will likely capture the imagination of the public and policy makers-who make funding decisions. Thus, there is a potential threat that funding for the development of infrastructure for CAVs may reduce funds available for public transportation.

\section{Limitations of Increasingly Automated and Connected Vehicles}

Increasing automobile use has its limits, however, particularly in large metropolitan areas and cities - where public transportation demand is strongest today. Current roadway capacity in many metropolitan areas and in most cities cannot absorb large numbers of additional cars during peak hours without creating worsening traffic congestion-even if new technology may reduce the amount of space needed to operate cars. Greater traffic volumes are especially likely if CAVs will be largely privately owned and increase suburban sprawl. Currently, building more urban freeways in cities does not seem politically feasible. Thus, public transportation's space efficiency during peak-hour commutes will remain a key strength in metropolitan areas and central cities. 
Similarly, implementing CAVs will be most difficult on city streets with complex roadway environments including pedestrians, cyclists, public transportation, drivers accessing parked cars, and delivery vehicles double parking. Thus, in cities where public transportation demand is greatest, CAVs face significant technological challenges. Lastly, newly developed automated and connected vehicle technology will initially be expensive and not affordable for everyoneparticularly the poor. Thus, public transportation will retain its crucial role in guaranteeing mobility for all.

\section{Automated and Connected Public Transport Vehicles}

Transit vehicles equipped with automated and connected technology could help make public transportation service more attractive and increase public transportation demand. For example, in the suburbs automated and connected buses could transport passengers from and to public transportation stations to access bus rapid transit, light rail, regional rail, or metrorail. Routes of these automated buses could be flexible based on customer demand. Automated and connected public transportation vehicles could also take advantage of any special lanes designated for the sole use of automated and connected vehicles in the suburbs and in cities-speeding up and increasing the reliability of buses. Some experiments also show that automated and connected buses can travel designated routes in complex urban environments, but they typically drive very slowly and face the same challenges as automated and connected cars in difficult urban roadway environments (Gibbs 2016).

Automated and connected feeder buses can increase the catchment area of public transportation in the suburbs, help solve the "last mile" problem, and allow public transportation agencies to get closer to serving passenger trips from origin to destination rather than only between transit stops. Even if buses are not fully automated, increasing connection to and information exchange with public infrastructure and other public transportation vehicles can help increase public transportation's attractiveness. Connected bus vehicles can trigger advanced green lights or communicate about passenger transfers with other vehicles at important transfer nodes (Vuchic 2005). This could result in increased bus travel speeds, more reliable trips, and greater customer satisfaction. Connected buses can also help improve real-time information for customers about arrivals and departures.

\section{Integration of Public Transportation with Other Mobility Services}

Over the next 30 years, public transportation agencies have to increasingly integrate their services with other mobility options. Some scholars argue that mobility should be seen as a service - an emerging concept known as Mobility as a Service (MaaS) (Heikkilä 2014). MaaS operators integrate information about public transportation, bikesharing, carsharing, and ridesharing services in an online platform. The goal of these online interfaces is to provide information on alternatives to single occupancy car travel and to use existing infrastructure and transportation networks more efficiently.

Customers can query that online database by entering their travel needs and preferences. MaaS provides real-time options for travel based on customer preferences and data about transit, bikesharing, carsharing, and ridesharing. Customers can purchase mobility services 
from these operators. It will be important for public transportation operators to link into MaaS-like services to connect with potential riders and to provide access and egress options from transit-through bikesharing, carsharing, or ridesharing. Providing access to carsharing, ridesharing, and bikesharing also gives mobility options to public transportation passengers outside of peak hours when transit service is less frequent. Some public transportation providers could become MaaS operators themselves or collaborate with others in mobility agencies shaping this transition towards MaaS-ideally integrating not just information, but also ticketing and payment into one transaction.

The MaaS concept can also link directly into a current trend toward greater multimodal travel in urban areas. Multimodal travelers use multiple modes of transportation during a day or week - versus relying on just one mode, typically the car, for all trips (Buehler \& Hamre 2015; Scheiner et al. 2016). Public transportation passengers are by definition multimodal, because of access and egress trips made by modes other than public transportation. Thus, combining information about public transportation with data on other modes will greatly enhance the convenience of public transportation.

\section{Regional Coordination and Integration of Public Transportation Services}

Competing with increasingly convenient automated vehicles requires public transportation agencies to make their services more attractive. One key element will be the coordination of public transportation services across jurisdictional boundaries and between operators. Passengers travel from trip origins to trip destinations. They do not care about the servicearea boundaries of public transportation drawn on a map by local governments or transit operators. Thus, in the coming 30 years public transportation agencies and governments will increasingly strive to coordinate their services, ticketing, and marketing regionally to provide more attractive and seamless service. This requires regional collaboration between local jurisdictions that fund and plan for public transportation. In addition, public transportation agencies themselves need to coordinate their services, ticketing, and marketing to assure seamless transfers between modes and operators. This coordination could go beyond local public transportation and include connections to airports and intercity rail service.

Verkehrsverbünde (VVs) in Germany, Switzerland, and Austria can provide lessons for the provision of seamless regional public transportation in the United States (Buehler, Zimmerman, \& Lukacs 2015; Koch \& Newmark 2017). VVs typically consist of local jurisdictions and the public transportation agency. Jointly they collaborate to provide tickets valid on all public transportation vehicles in the entire region-including steeply discounted monthly, annual, and tickets for special groups (e.g., students). Monthly and annual tickets mimic the cost structure of automobile use, where most of the cost occurs up-front, such as the car purchase, registration fees, insurance, or filling up the gas tank. The cost per individual trip is very low or zero. In addition, in VVs public transportation agencies share marketing and branding to assure consistent messaging for customers. VVs also facilitate coordination of planning for public transportation in the region and assist in the distribution of fare revenue across operators. Lastly, VVs help provide customer information and service. 


\section{Coordinating Planning for Public Transportation and Land Use}

Demand for public transportation is highest in urban areas with greater population densities and a mix of land uses (Buehler \& Pucher 2012; Ewing \& Cervero 2010). Assuring attractive public transportation service in the future requires state and local governments to integrate planning for land-use and public transportation. Planning approaches like Transit Oriented Development (TOD) are most promising_clustering higher density, mixed-use developments around public transportation stops (Reconnecting America 2011). TOD can boost ridership because it increases the number of trip origins and destinations that are easily accessible by public transportation. Some Metropolitan areas, such as Denver and Portland, have already shown how long-term planning can help coordinate public transportation and land-use (Ewing \& Hamidi 2014; RTD 2017). By contrast, future development based on low-density sprawl with separated land uses will be very difficult to serve by public transportation. However, land use in current suburban locations can be adapted to accommodate public transportation service. This is a long-term process. One of the most ambitious current projects in the United States is probably at Tysons in Fairfax County, Virginia. Zoning changes and new Metrorail stops are set to transform Tysons from a single-use car-oriented commercial area into a mixed-use urban area, home to 100,000 new residents by 2050 (Fairfax County 2017). Public transportation will serve as the connector between these new "urban islands" in a sea of suburban sprawl.

\section{Concluding Thoughts}

More convenient car travel because of increasingly automated and connected vehicles will pose a threat to public transportation demand over the next 30 years. However, CAV technology faces difficult conditions in urbanized areas with complex street environments and limited roadway capacity_-particularly during peak commute hours. Public transportation demand is greatest in urban areas, because public transportation is very space efficient and can transport large amounts of people during rush hour. Thus, public transportation will be most competitive compared to CAVs in urbanized areas and during commute hours. In addition, the initial high cost of CAVs will put those cars out of financial reach for many current public transportation riders. Thus, public transportation will retain its important role in assuring mobility for all.

Given its competitive advantages compared to CAVs and its social inclusiveness, public transportation ridership in metropolitan areas in general and in cities in particular will likely increase over the next 30 years. However, public transportation and governments will have to make public transportation more attractive to compete effectively with cars that are more convenient. Above all, this requires customer orientation and a focus on how to make public transportation more attractive and competitive compared to the car. This includes exploring the use of emerging automated and connected technologies for public transportation, integrating public transportation with other mobility services, regional coordination and integration of public transportation services, and coordinating planning for public transportation and land use. In addition, governments will have to assure adequate funding for public transportation - and resist the push to shift funds from public transportation to CAVs. This is particularly important when considering public transportation riders with lower incomes who are least likely to afford expensive new CAVs. 
Planning for the future of public transportation has to start now, because of the long-term nature of infrastructure projects and slow changes in the built environment. For sure, nobody will ride public transportation systems that are never built and nobody will live in TODs that do not exist. Above all, customers of the future, as today, will ride public transportation if it is fast, convenient, reliable, safe, clean, and attractively priced.

\section{Acknowledgements}

I would like to thank Mariia Zimmerman for her constructive comments that helped improve upon an earlier draft. Virginia Tech graduate student Bryan Botello contributed to a literature search on automated and connected vehicles. This literature search was part of the research project "Planning for walking and cycling in an automated vehicle future," funded by the Virginia Center for Transportation Innovation and Research (MATS-UTC).

\section{References}

APTA. 2017. 2016 Public Transportation Fact Book, 67th Edition. Washington, DC: American Public Transportation Association. http://www.apta.com/resources/statistics/Documents/ FactBook/2016-APTA-Fact-Book.pdf

BFS. 2017. Mobility and Transport 2015. Bern, CH: Bundesamt fuer Statistik/Swiss Federal Office for Statistics.

BMVIT - Bundesminiterium für Verkehr, Innovation und Technologie. 2015. Osterreich Unterwegs 2013/2014. Travel survey. Vienna, Austria.

Buehler, R. and A. Hamre. 2015. "The multimodal majority? Driving, walking, cycling, and public transportation use among American adults." Transportation, 42(6), 1081-1101. doi:10.1007/s11116-014-9556-z

Buehler, R., W. Jung, and A. Hamre. 2015. "Planning for Sustainable Transport in Germany and the USA: A Comparison of the Washington, DC and Stuttgart Regions." International Planning Studies, 20(3), 292-312. doi:10.1080/13563475.2014.989820

Buehler, R. and J. Pucher. 2012. "Demand for Public Transport in Germany and the USA: An Analysis of Rider Characteristics." Transport Reviews, 32(5), 541-567.

Buehler, R., M. Zimmerman, and K. Lukacs. 2015. Regional Coordination in Public Transportation: Lessons from Germany, Austria, and Switzerland. Washington DC: Report prepared for the Mid-Atlantic University Transportation Research Consortium (MAUTC), University Park, PA, as part of the U.S. Department of Transportation's Research and Innovative Technology Administration, Washington, D.C. http://www.mautc.psu.edu/ docs/VT-2013-04.pdf

DfT. 2017. National Travel Statistics. London, UK: Department for Transport.

DMT. 2017. Danish National Travel Surveys. Copenhagen: Technical University of Denmark, Department of Transport. 
Ewing, R. and R. Cervero. 2010. "Travel and the Built Environment: A Meta-Analysis." Journal of the American Planning Association, 76(3), 265-294. doi: 10.1080/01944361003766766

Ewing, R., and S. Hamidi. 2014. "Longitudinal Analysis of Transit's Land Use Multiplier in Portland (OR)." Journal of the American Planning Association, 80(2), 123-137. doi:10.1080/01 944363.2014 .949506

Fairfax County. 2017. "Transforming Tysons." Retrieved from https://www.fairfaxcounty.gov/tysons/

Gibbs, S. 2016. "Self-driving buses take to roads alongside commuter traffic in Helsinki." The Guardian. https://www.theguardian.com/technology/2016/aug/18/self-driving-buseshelsinki

Heikkilä, S. 2014. Mobility as a Service - A Proposal for Action for the Public Administration, Case Helsinki. Master's thesis. Helsinki, Finland: Aalto University. http://urn.fi/URN:NBN:fi:a alto-201405221895

Koch, M. and G. Newmark. 2017. "Legislating Transit Coopetition': Privatization and Planning Devolution in Germany." Transportation Research Record: Journal of the Transportation Research Board, 2543: 45-51. doi: 10.3141/2543-05

Litman, T. 2017. Autonomous Vehicle Implementation Predictions: Implications for Transport Planning. Victoria, Canada: Victoria Transport Policy Institute (VTPI). https://www.vtpi. org/avip.pdf

MOP. 2017. The German Mobility Panel. Karlsruhe: Karlsruhe Institute of Technology.

MWCOG. 2010. 2007/2008 TPB Household Travel Survey-Technical Documentation. Washington, DC: National Capital Region Transportation Planning Board, Metropolitan Washington Council of Governments (MWCOG).

Newman, P. and J. Kenworthy. 2011. "'Peak Car Use': Understanding the Demise of Automobile Dependence." World Transport Policy and Practice, 17(2): 31-42.

NYMTC. 2014. 2010/2011 Regional Household Travel Survey Final Report. New York City: New York Metropolitan Transportation Council (NYMTC). https://www.nymtc.org/portals/0/ pdf/RHTS/RHTS_FinalReport\%2010.6.2014.pdf

OMNIL. 2011. Mobility in the Isle de France Region 2010 (EGT - Enquêtes Globales Transport). Paris: Observatoire de la mobilité en ^le de France (OMNIL)

Pucher, J. 2004. Public Transportation. In S. Hanson and G. Giuliano (eds.), The Geography of Urban Transportation, Third Edition (pp. 199-236). New York: Guilford Press.

Reconnecting America. 2011. TOD 204: Planning for TOD at the Regional Scale. The Center for Transit-Oriented Development. http://ctod.org/pdfs/tod204.pdf

RTD. 2017. FasTracks. Denver, Colorado. http://www.rtd-denver.com/Fastracks.shtml

Scheiner, J., K. Chatterjee, and E. Heinen. 2016. "Key events and multimodality: a life course approach." Transportation Research Part A: Policy and Practice, 91: 148-165. doi:10.1016/j. tra.2016.06.028 
Shoup, D. 2011. The High Cost of Free Parking. Chicago: Planners Press, American Planning Association.

SIKA. 2017. SIKA Statistics: The National Travel Survey. Östersund, Sweden: Swedish Institute for Transport and Communications Analysis.

TOI. 2015. Norwegian Travel Survey Key Results. Oslo, Norway: Institut of Transport Economics, TOI.

TRB. 2001. Making Transit Work: Insight from Western Europe, Canada, and the United States. Transportation Research Board Special Report 257. Washington DC: National Academy Press. http://onlinepubs.trb.org/onlinepubs/sr/sr257.pdf

USDOT. 2010. Summary of Travel Trends: 2009 National Household Travel Survey (NHTS). Washington, DC: U.S. Department of Transportation, Federal Highway Administration. http://nhts.ornl.gov/2009/pub/stt.pdf

USDOT. 2017. Automated Vehicle Research. Washington, DC: U.S. Department of Transportation, Office of the Assistant Secretary for Research and Technology (OST-R). https://www.its.dot.gov/automated_vehicle/

Vuchic, V. 2005. Urban Transit: Operations, Planning, and Economics. Hoboken, NJ: Wiley \& Sons.

WSP. 2011. National Travel Survey. Finnish Transport Agency. Helsinki: WSP Finnland.

Zmud, J., M. Tooley, T. Baker, and J. Wagner. 2015. Paths of Automated and Connected Vehicle Deployment: Strategic Roadmap for State and Local Transportation Agencies. College Station, TX: Texas A\&M Transportation Institute. https://static.tti.tamu.edu/tti.tamu.edu/ documents/161504-1.pdf

\section{About the Author}

Ralph BuehleR, PH.D. (https://ralphbu.wordpress.com/) is associate professor in urban affairs and planning at Virginia Tech's Alexandria Center. He is author or co-author of over 50 refereed articles in academic journals, the book City Cycling (MIT Press), as well as reports to federal and local governments, NGOs, and for profit industry organizations. Most of his research has an international comparative perspective, contrasting transport and land-use policies, transport systems, and travel behavior in Western Europe and North America. 